\title{
Correlation of the Emergency Handling Peak Ground Acceleration (PGA) for High-speed Railway and Strong-motion Indices using K-net Data
}

\author{
BAI Linjuan ${ }^{1, a}$ \\ ${ }^{1}$ Key Laboratory of Earthquake Engineering and Engineering Vibration, Institute of Engineering \\ Mechanics, China Earthquake Administration, Harbin 150080, China \\ a1009282186@qq.com
}

\begin{abstract}
Keywords: Emergency Handling; Peak Ground Acceleration; High-speed Railway; Strong Motion. Abstract. The emergency handling Peak Ground Acceleration (PGA) has been used as a measure of braking for High-speed Railway (Shinkansen) during earthquake in Japan, and it necessitates to know the correlation between PGA and other strong motion indices, e.g. un-filtered Peak Ground Acceleration $\left(\mathrm{PGA}_{\mathrm{u}}\right)$, Japan Meteorological Agency seismic instrumental intensity $\left(\mathrm{I}_{\mathrm{JMA}}\right)$, Spectrum Intensity (SI), Arias Intensity $\left(\mathrm{I}_{\mathrm{a}}\right.$ ), Cumulative Absolute Velocity (CAV), and Cumulative Differential of Energy (DE). The PGA and other ground motion indices were calculated using the selected data set from K-net, in which consists of 2714 three-component records selected from 16 earthquake events occurred in Japan. The relationships between the PGA, and PGA $\mathrm{I}_{\mathrm{u}}, \mathrm{SI}, \mathrm{I}_{\mathrm{a}}, \mathrm{CAV}$, and DE were then derived performing a linear regression analysis. Our Results indicate that the PGA shows higher correlation with $\mathrm{I}_{\mathrm{JMA}}$ or SI than other ground motion indices, which may be useful for deployment of new parameters of emergency handling during earthquake for High-speed Railway.
\end{abstract}

\section{Introduction}

The emergency handling Peak Ground Acceleration (PGA) has been used as a measure of braking for High-speed Railway (Shinkansen) during earthquake in Japan for many years. It was defined as maximum of vector composition of two horizontal components, which are processed using a casual Butterworth filter with a low-pass frequency of $5 \mathrm{~Hz}$ [1]. The seismometers were installed every 20 to $25 \mathrm{~km}$ along the Shinkansen line to issue an alarm if the PGA exceeds $40 \mathrm{gal}\left(\mathrm{cm} / \mathrm{s}^{2}\right)$ [2]. China is an earthquake-prone country. Earthquake is a natural disaster which probability is small but hazards to railway safety is high. With the rapid development of high-speed railway, it is urgent for Chinese high-speed railway construction of earthquake emergency handling system [3].

Other ground motion indices, e.g., Japan Meteorological Agency seismic instrumental intensity $\left(\mathrm{I}_{\mathrm{JMA}}\right)$ [4], Spectrum Intensity (SI) [5], Arias Intensity ( $\mathrm{I}_{\mathrm{a}}$ ) [6], Cumulative Absolute Velocity (CAV) [7], and Cumulative Differential of Energy (DE) [8], etc., are also used to describe the severity of an earthquake. Hence, it is important to know the relationship between the PGA and other strong motion parameters (e.g., I IMA, SI, I $\mathrm{I}_{\mathrm{a}}, \mathrm{CAV}, \mathrm{DE}$ ).

In this study, the PGA and other ground motion indices were calculated using the selected data set from K-net, in which consists of 2714 three-component records selected from 16 earthquake events occurred in Japan. The relationships between the PGA, and PGA $\mathrm{A}_{\mathrm{u}}, \mathrm{I}_{\mathrm{JMA}}, \mathrm{SI}, \mathrm{I}_{\mathrm{a}}, \mathrm{CAV}$, and DE were then derived performing a linear regression analysis, which may be useful for deployment of new parameters of emergency handling during earthquake for High-speed Railway.

\section{Data}

The data set used in this study consists of 2714 three-component acceleration records selected from 16 earthquake events occurred in Japan, with magnitude ranges from 5.8 to 7.3. The acceleration signals were then integrated once for obtaining the velocities. After the integration process, the velocities were recursively processed using a casual Butterworth filter with a high-pass frequency of $0.075 \mathrm{~Hz}$ for removing the low-frequency drift. Fig. 1 shows the distributions of the epicenters and the K-net stations used in this study. 


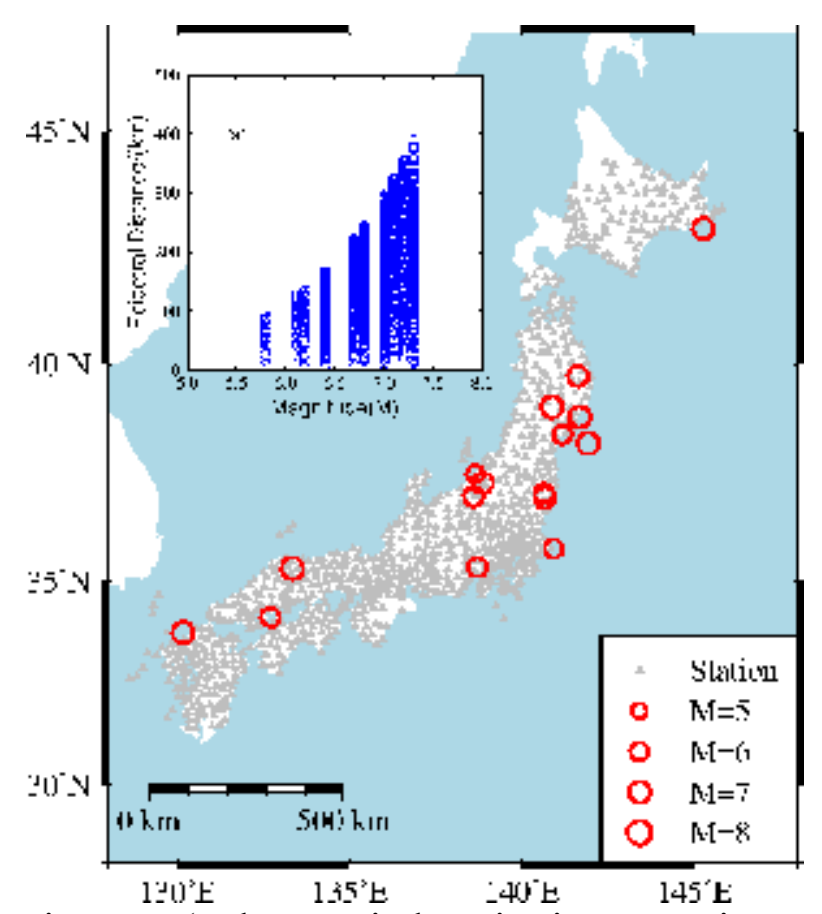

Fig. 1 Distribution of the epicenters (red open circles, size in proportion to magnitude) and the K-net stations (grey solid triangles) used in this study. (a) Distribution of K-net data (blue open circles used in this study as a function of the magnitude and epicentral distance

\section{Strong-motion Indices}

The emergency handling Peak Ground Acceleration (PGA) are defined as maximum of vector composition of two horizontal components, which are processed using a casual Butterworth filter with a low-pass frequency of $5 \mathrm{~Hz}$. Similarly, un-filtered Peak Ground Acceleration $\left(\mathrm{PGA}_{\mathrm{u}}\right)$ are defined as maximum of vector composition of two horizontal components un-filtered. Japan Meteorological Agency seismic instrumental intensity $\left(\mathrm{I}_{\mathrm{JMA}}\right)$, Spectrum Intensity $(\mathrm{SI})$, Arias Intensity $\left(\mathrm{I}_{\mathrm{a}}\right)$, Cumulative Absolute Velocity (CAV), and Cumulative Differential of Energy (DE) are defined in reference $[4,5,6,7,8]$, respectively.

\section{Results}

The regression model used in this study is given as

$$
\log _{10} \mathrm{y}=\mathrm{a} \cdot \log _{10} \mathrm{x}+\mathrm{b}
$$

where $y$ is the PGA, $a$ and $b$ are the regression coefficients, and $x$ is the ground motion indices, i.e., $\mathrm{PGA}_{\mathrm{u}}, \mathrm{I}_{\mathrm{JMA}}, \mathrm{SI}, \mathrm{I}_{\mathrm{a}}, \mathrm{CAV}$, and DE. The regression models given in Equation (1) is linear with respect to the coefficients to be determined.

Fig. 2(a) shows the relationship between PGA and SI, Fig. 2(b) shows the relationship between PGA and $\mathrm{PGA}_{\mathrm{u}}$, Fig. 2(c) shows the relationship between PGA and $\mathrm{I}_{\mathrm{JMA}}$, Fig. 2(d) shows the relationship between PGA and $I_{a}$, Fig. 2(e) shows the relationship between PGA and DE, and Fig. 2(f) shows the relationship between PGA and CAV for the K-net data used in this study, respectively. The regression coefficients, $\mathrm{a}, \mathrm{b}$, and correlation coefficient of each relationship are indicated in corresponding sub-figure.

From the Fig. 2, we find that the PGA shows the highest correlation with SI, it shows the second highest correlation with the parameters such as $\mathrm{I}_{\mathrm{JMA}}$, and it shows the next higher correlation with $\mathrm{I}_{\mathrm{a}}$, through correlation analysis used K-net data in Japan in this study. 


\section{Conclusions and Discussions}

The PGA and other strong motion parameters (e.g., IJMA, SI, $\mathrm{I}_{\mathrm{a}}, \mathrm{CAV}, \mathrm{DE}$ ) were calculated using K-net data set in this study, in which consists of 2714 three-component records selected from 16 earthquake events occurred in Japan. The relationships between the PGA, and PGA $\mathrm{u}_{\mathrm{u}}, \mathrm{I}_{\mathrm{JMA}}, \mathrm{SI}, \mathrm{I}_{\mathrm{a}}, \mathrm{CAV}$, and DE were then derived performing a linear regression analysis. The major findings are as follows:
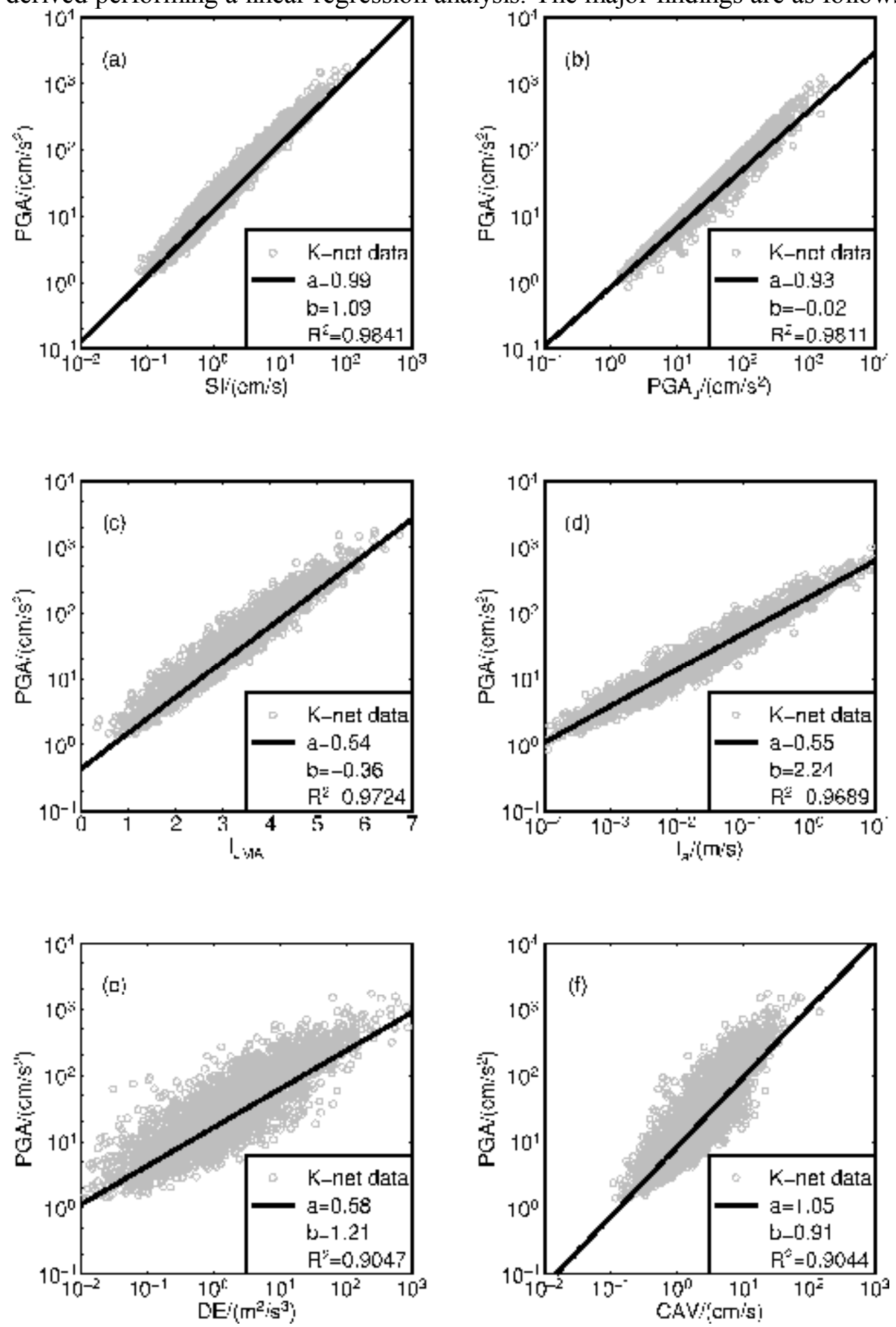

Fig. 2 Relationships between (a) PGA and SI, (b) PGA and PGA ${ }_{u}$, (c) PGA and $\mathrm{I}_{\mathrm{JMA}}$, (d) PGA and $\mathrm{I}_{\mathrm{a}}$,

(e) PGA and DE, and (f) PGA and CAV for the K-net data (grey open circles) used in this study, respectively. The black solid lines show the empirical scaling relationships between the PGA and other strong motion parameters (e.g., $\left.\mathrm{I}_{\mathrm{JMA}}, \mathrm{PGA}_{\mathrm{u}}, \mathrm{SI}, \mathrm{I}_{\mathrm{a}}, \mathrm{CAV}, \mathrm{DE}\right)$.

1. The results show that there are certain linear correlations between the PGA and other strong motion parameters. 
2. Comparing the correlation coefficients between the JMA intensity with all strong motion parameters, it follows as: (a) the PGA shows the highest correlation with SI, (b) it shows the second highest correlation with the parameters such as $\mathrm{I}_{\mathrm{JMA}}$, and (c) it shows the next higher correlation with Ia.

3. From the obtained relationship in this study, it was found that the PGA shows higher correlation with $\mathrm{I}_{\mathrm{JMA}}$ or SI than other ground motion indices, which may be useful for deployment of new parameters of emergency handling during earthquake for High-speed Railway.

\section{Acknowledgements}

Data for this study are provided by China Strong Motion Network Centre at Institute of Engineering Mechanics, China Earthquake Administration. This work was supported by Scientific Research Fund of Institute of Engineering Mechanics, China Earthquake Administration (2016A03), National Natural Science Foundation of China (51408564, U1534202) and Program for Innovative R\&D Team in China Earthquake Administration.

\section{References}

[1] Nakamura H, IWATA N, ASHIYA K. RTRI Report, 2005, 19(10): 11-16 (in Japanese)

[2] Nakamura Y, Saita J. Earthquake Early Warning Systems, ed. Gasparini P, ManfreDE G, Zschau J, Berlin and Heidelberg: Springer, 2007

[3] SONG J D. Institute of Engineering Mechanics, China Earthquake Administration. 2013 (in Chinese)

[4] Japan Meteorological Agency. Gyosei, 1996 (in Japanese)

[5] Housner G. In: Proceedings Symposium on Earthquake and Blast Effects on Structures, Los Angeles, California, June 1952

[6] Arias A. Hansen R J, ed. Seismic Design for Nuclear Power Plants, MIT Press, Cambridge, Massachusetts, 1970

[7] Electric Power Research Institute. EPRI Report NP-5930, 1988

[8] Nakamura Y. Proceedings of Early Warning Conference '98, Germany, 1998 